\title{
Minimum effective anaesthetic concentration of hyperbaric lidocaine for spinal anaesthesia
}

Philip W.H. Peng MB BS FRCPC, Vincent W.S. Chan MD FRCPC, Anahi Perlas MD

Purpose: Minimum effective anaesthetic concentration (MEAC) of lidocaine for spinal anaesthesia, defined as the concentration at which a spinal anaesthetic agent produces surgical anaesthesia within 20 min of administration in $50 \%$ of patients, was determined in a randomised, double-blind study in young patients undergoing knee and ankle surgery. Methods: Using the combined spinal-epidural technique, 48 or $72 \mathrm{mg}$ hyperbaric lidocaine containing dextrose $7.5 \%$ was administered intrathecally to 43 patients at concentrations ranging from $0.2-0.9 \%$. The choice of lidocaine concentration was determined by Dixon's up-and-down method. Complete anaesthesia was defined as: (I) pinprick anaesthesia at or higher than $T_{12}$, (2) anaesthesia to transcutaneous tetanic electric stimulation ( $50 \mathrm{~Hz}$ at $60 \mathrm{~mA}$ for five seconds) in the knees and (3) complete leg paralysis; all occurring in both lower extremities within 20 min. Epidural anaesthesia was initiated if anaesthesia was incomplete.

Results: In the $48 \mathrm{mg}$ group, MEAC was $0.54 \%$ (95\% Cl-0.21-0.87). Anaesthetic effect was variable with mean duration of anaesthesia of $29 \mathrm{~min}$ (range: $20-50 \mathrm{~min}$ ) and maximum pinprick sensory level ranging from $\mathrm{T}_{2} \mathrm{~T}_{10}$. In the $72 \mathrm{mg}$ group, successful anaesthesia was achieved consistently at a concentration of $0.3 \%$, i.e., MEAC was $<0.3 \%$. Mean duration of complete anaesthesia was $46 \mathrm{~min}$ (range: $30-60 \mathrm{~min}$ ) with maximum sensory level from $T_{3} T_{8}$.

Discussion: Spinal anaesthesia can be accomplished with very dilute lidocaine solutions $(<0.9 \%)$. The value of MEAC is dose-dependent, i.e., complete anaesthesia can be accomplished with lower concentrations by increasing the dose of spinal anaesthetic administered.

Objectif : Déterminer la concentration anesthésique minimale efficace (CAME) de lidocaîne pour anesthésie rachidienne. Cette CAME est définic comme la concentration à laquelle l'agent anesthésique produit une anesthésie chirurgicale chez $50 \%$ des patients dans un délai de 20 minutes après l'injection. L'étude a été réalisée à double insu et selon une distribution aléatoire chez de jeunes patients soumis à une chirurgie de la cheville ou du genou.

Méthodes : Utilisant une technique combinée de rachi-épidurale, de la licocaine rendue hyperbare avec du dextrose $7.5 \%$ a été administrée en sous arachnoïdien à raison de 48 ou $72 \mathrm{mg}$ chez 43 patients en concentrations variant de 0,2 à $0,9 \%$. Le choix des concentrations de lidocaine était déterminé par la méthode des hauts et bas de Dixon. Une anesthésie complete était définie par : I-une anesthésie à la piqûre à $T_{12}$ ou plus hauti: 2-une anesthésie à une stimulation électrique tétanique percutanée au niveau des genoux $(50 \mathrm{~Hz}, 60 \mathrm{~mA}$ et $5 \mathrm{sec}$ ); 3-une paralysie complète des jambes; toutes ces manifestations devaient être présentes aux deux jambes en moins de 20 minures. Si l'anesthésie était incomplète, la relève était assurée par l'épidurale.

Résultats : Dans le groupe $48 \mathrm{mg}$, la CAME était de 0,54\% (intervalle de confiance 95\%-0,21 à 0,87\%), L'effet anesthésique était variable avec une durée moyenne de $29 \mathrm{~min}$. (écart $20-50 \mathrm{~min}$.) et un niveau sensitif à l'aiguille variant de $T_{2}$ à $T_{\text {go }}$. Dans le groupe $72 \mathrm{mg}$, une anesthésie adéquate était atteinte de façon fiable à une concentration de $0,3 \%$, c'est-à-dire que la CAME était $<0,3 \%$. La durée moyenne de l'anesthésie complète était de 46 minutes (écart 30-60 min.) avec un niveau sensitif maximal variant de $T_{3}$ à $T_{8^{\prime}}$

Discussion : L'anesthésie rachidienne peut être réussie avec des solutions de lidocaïne très diluées $(<0,9 \%)$. La valeur de la CAME dépend de la dose, i.e., une anesthésie complète peut être réalisée avec des concentrations pilus faibles à condition d'augmenter la dose d'anesthésique local administré.

From the Department of Anaesthesia, The Toronto and Mount Sinai Hospital, University of Toronto, 399 Bathurst Street, Toronto, Ontario, Canada M5T 2 S8.

Address correspondence to: Dr. Vincent Chan, Department of Anacsthesia, The Toronto Hospital, Western Division, 399 Bathurst Street, Toronto, Ontario, Canada M5T $2 S 8$.

Presented, in part, at the Canadian Anaesthetists' Sociery Meering in Vancouver in June 1997. Research was supported by the Astra Pharm Inc. Canadian Research Award in Anaesthesia.

Accepted for publication Nopember 9, 1997 


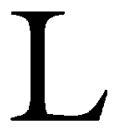

IDOCAINE was the first synthetic aminoamide local anaesthetic and has been used for spinal anaesthesia since 1948.' Traditionally, hyperbaric lidocaine solution at a concentration of $5 \%$ in dextrose $7.5 \%$ is the commonest preparation for spinal anaesthesia. In a multicentre prospective study of over 10,000 patients, lidocaine $5 \%$ solution administered intrathecally in 40-100 $\mathrm{mg}$ did not result in any major neurological complication. ${ }^{2}$ However, recent reports of major and minor neurological complications, i.e., cauda equina syndrome and transient radicular irritation respectively, following intrathecal use of hyperbaric lidocaine $5 \%$ raise the concern of safety about its use..$^{3-5}$

Animal studies using the desheathed nerve preparation of frog showed that exposure to lidocaine $5 \%$ solution for $15 \mathrm{~min}$ irreversibly extinguished the compound action potential and the median neurotoxic concentration was found to be $1 \% .{ }^{6,7}$ In mammals, a lidocaine solution of $3 \%$ concentration was neurotoxic to the sciatic nerve in pivo. ${ }^{8}$ In humans, neurotoxicity has been reported in a paticnt following accidental spinal injection of lidocaine $2 \%$ intended for epidural use. ${ }^{9}$ On the other hand, there is a growing interest in using dilute lidocaine solution for spinal anaesthesia. Spinal lidocaine $1.5-2 \%$ in a dose of $50-80 \mathrm{mg}$ produces effective anaesthesia in a variety of urological and obstetrical conditions. ${ }^{10-13}$ Furthermore, lidocaine $0.5 \%$, either hyperbaric or hypobaric, can produce effective spinal anaesthesia for perirectal and urological surgery with doses ranging between $30-40$ mg. ${ }^{14,15}$ However, the lowest effective concentration of lidocaine for spinal anaesthesia in humans has not been determined.

Review of reports concerning neurological injury associated with continuous spinal anaesthesia led us to believe that anaesthetics should be administered at the lowest effective concentration. ${ }^{3}$ The aim of this study was to determine the minimum effecrive anaesthetic concentration (MEAC) of lidocaine for spinal anaesthesia, which is defined as the concentration at which a spinal anaesthetic agent produces surgical anaesthesia within $20 \mathrm{~min}$ of administration in $50 \%$ of patients. This concept is similar to the concept of minimum alveolar concentration (MAC) for inhalation anaesthetic. Furthermore, as MEAC may vary with the administered dose, it will be determined using two doses of lidocaine.

\section{Methods}

We conducted a prospective, randomised, doubleblind study to determine the MEAC of lidocaine for spinal anaesthesia at doses of 48 and $72 \mathrm{mg}$ for young patients. After institutional ethics committee approval, informed consent was obtained from 43 ASA I-III patients (age $18-42 \mathrm{yr}$, weight $50-115 \mathrm{~kg}$, height 150-190 cm) undergoing lower limb arthroscopic surgery. All patients had no contraindication to spinal or epidural anaesthesia.

\section{Patient preparation}

Patients were randomly assigned to receive spinal lidocaine at low dose $(48 \mathrm{mg})$ or high dose $(72 \mathrm{mg})$. Within each treatment group, the concentration of the hyperbaric lidocaine solution administered ranged from $0.2-0.9 \%$ while the dose was kept constant. Selection of the range of lidocaine concentration to be tested was based on our preliminary data. ${ }^{a}$ Each parient received a preselected concentration of spinal lidocaine based on the modified Dixon's up-and-down method, ${ }^{16}$ i.e., depending on the response of the previous concentration, the concentration for the next patient would be adjusted up or down in increments of $0.1 \%$. For example, if a patient developed complete anaesthesia after a given concentration, the next patient in the same treatment group would receive lidocaine solution at $0.1 \%$ lower concentration. On the other hand, if anaesthesia was incomplete, the lidocaine concentration would be adjusted upwards by $0.1 \%$ in the next patient. The anaesthetist performing the spinal anaesthesia was aware of the nature of the lidocaine solution but both the patient and the investigator performing neurological assessment were blinded.

The spinal hyperbaric lidocaine solution tested was prepared by one of the anaesthetists not involved in the patient's intraoperative assessment. It was prepared by mixing hyperbaric lidocaine $5 \%$ (Astra Pharma-Inc, Mississauga, Ontario) with plain dextrose $7.5 \%$ solution. The dextrose $7.5 \%$ solution was prepared by mixing dextrose $10 \%$ solution with sterile water in $3: 1$ ratio. The dextrose $10 \%$ solution is available as a $3 \mathrm{ml}$ ampoule (Baxter Healthcare Corporation, Deerfield IL). Depending on the selected concentration ( $0.2-0.9 \%)$ and dose (48 or $72 \mathrm{mg}$ ), the total volume ranged from $5.3-36 \mathrm{ml}$, while keeping the dextrose concentration constant at $7.5 \%$. For example, a $0.4 \%$ solution was prepared by adding $1.6 \mathrm{ml}$ lidocaine $5 \%$ solution $(80 \mathrm{mg}$ ) to $18.4 \mathrm{ml} \mathrm{dex}$ trose $7.5 \%$ solution. Twelve and eighteen $\mathrm{ml}$ of this final solution would then be used for the dose of $48 \mathrm{mg}$ and $72 \mathrm{mg}$ respectively.

a PWH Peng, VWS Chan. the use of dilure hyperbaric lidocaine solution for spinal anesthesia in outpatient arthroscopic surgery. Presented at the Society for Ambulatory Anesthesia Meeting, Boston, Mass, April, 1996. 


\section{Preoperatipe management}

After reviewing patient's medical and anaesthetic history, physical examination and laboratory test, standard monitors (blood pressure cuff, pulse oximeter and ECG) were applied before commencing the procedure of combined spinal epidural. Patients were allowed to receive premedication of midazolam and fentanyl up to a maximum of $4 \mathrm{mg}$ and $100 \mu \mathrm{g}$ respectively and approximately $7 \mathrm{ml} \cdot \mathrm{kg}^{-1}$ normal saline for hydration before the induction of spinal anaesthesia.

With the patient in the lateral decubitus position, a Hustead \#17G 3 1/2 epidural needle was inserted at $\mathrm{L}_{2-3}$ or $\mathrm{L}_{3-4}$ level and the epidural space was localised with the loss of air resistance technique. Once in the epidural space, a \#26G 4 3/4 Whitacre spinal needle was inserted into the subarachnoid space with the orifice of the needle tip pointing towards the non-dependent side. After the studied solution of lidocaine had been injected at a rate of approximately $1 \mathrm{ml}$ per $5 \mathrm{sec}$, the spinal needle was withdrawn and a 20 -gauge epidural catheter was placed, leaving a $2-3 \mathrm{~cm}$ indwelling segment. The epidural needle was then removed and the patient was positioned supine for neurological assessment.

\section{Assessment}

Patients were assessed for a minimum of $20 \mathrm{~min}$ before surgery. Investigators, blinded to the concentration of lidocaine solution, performed the following tests: (1) pinprick sensory testing with a \#23G needle to determine the uppermost dermatomal level on both sides; (2) transcutaneous electrical stimulation by applying a nerve stimulator (Neuro Technology, Digi Stim III) to both knees. Current amplitude was gradually increased in $5 \mathrm{~mA}$ increments until a maximum of $60 \mathrm{~mA}$ or perception of pain by the patient (tetanic electrical stimulation of $50 \mathrm{~Hz}$ at $60 \mathrm{~mA}$ for $5 \mathrm{sec}$ was considered to be equivalent to surgical incision stimulation ${ }^{17}$ ); (3) degree of motor block was assessed using a modified Bromage scale $(0=$ no block, $1=$ hip movement block, 2 = hip and knee block, $3=$ complete block in hip, knee and ankle).

Complete anaesthesia was defined as loss of pinprick sensation $\geq T_{12}$ level bilaterally, loss of sensation to tetanic electrical stimulation at the knee bilaterally and motor block in both lower extremities within $20 \mathrm{~min}$.

If complete anaesthesia was not obtained after 20 min, $3 \mathrm{ml}$ lidocaine $1.5 \%$ with $1: 200,000$ epinephrine was injected epidurally to rule out intravenous injection. If the test result was negative, epidural anaesthesia was then provided with lidocaine $2 \%$ in $5 \mathrm{ml}$ increments. Once epidural anaesthesia was initiated, neurological assessment was stopped.

\section{Intraoperative and postoperatipe management}

During surgery, the sensory level above the site of surgery was assessed. If the sensory level regressed to $\mathrm{T}_{12}$ or the patient experienced any discomfort in the surgical site or from the thigh tourniquet, supplemental epidural lidocaine $2 \%$ solution was administered. During surgery, the patient may receive additional incremental doses of $50 \mu \mathrm{g}$ fentanyl (up to a total of $3 \mu \mathrm{g} \cdot \mathrm{kg}^{-1}$ ), $1 \mathrm{mg}$ midazolam (up to $0.1 \mathrm{mg} \cdot \mathrm{kg}^{-1}$ ) to relieve anxiety if necessary.

All patients were brought to the recovery room after surgery. Occurrence of post-dural puncture headache, back pain, neurological symptoms or transient radicular irritation (defined as pain and/or dysesthesia in the legs or buttocks after recovery from spinal anaesthesia ${ }^{18}$ ) was checked daily for three days through telephone interview or in person.

\section{Data collection}

Baseline demographic data and vital signs were collected before surgery. The type and duration of surgical procedure, and the type and dose of intravenous medication given perioperatively were documented. Neurological tests and haemodynamic data were performed every five minutes for the first $20 \mathrm{~min}$ and every $10 \mathrm{~min}$ thereafter. Incidence of hypotension (systolic blood pressure (30\% from the baseline) and the need for vasopressor (ephedrine) was aiso recorded.

\section{Statistical analysis and sample size}

Data are presented as mean \pm SD. Demographic data, haemodynamic measurement and anaesthetic data between groups were compared by student $t$ test for continuous variables and by Fisher's exact test analysis for nominal variables. Statistical significance $(P<0.05)$ for between group comparisons was based on a twotailed hypothesis. Correlation between the highest sensory level achieved with volume and concentration of lidocaine was determined with multiple linear regression analysis.

Determination of MEAC was carried out according to the formula of Dixon and Massey ${ }^{16}$ where estimated mean of MEAC is $\mathrm{X}=(\Sigma f i \mathrm{Xi} / n)+d / 2$

$(X i$-individual lidocaine concentration; $f i=$ frequency of failed block associated with a given concentration; $\mathrm{n}=$ total number of patients with failed block and $\mathrm{d}=$ concentration increment of $0.1 \%$ )

The calculation of $95 \%$ confidence interval for the MEAC is shown in Appendix.

Based on Dixon's up-and-down method and data from previous studies ${ }^{19}$ using the same method, we estimated the sample size to be $\mathbf{3 0}$ in each treatment group. 


\section{Results}

There were no differences in the demographic data between the two dose groups (Table I). All operations performed were knee arthroscopy except for three patients in the $48 \mathrm{mg}$ group who had ankle surgery. No difference was found in the amount of intravenous fluid used perioperatively or the duration of surgery between the groups (Table I). Furthermore, no difference was found in the number of patients receiving premedication and the amount of premedication used for the spinal anaesthesia between the two dose groups (Table I).

The value of MEAC was dose dependent. In the 48 mg group (Figure 1), 35 patients were recruited and MEAC of hyperbaric lidocaine was $0.54 \%$ (95\% CI $0.21-0.87)$. The anaesthetic effect was variable with incomplete anaesthesia in 16 patients. In the remaining 19 patients, although anaesthesia was complete, anaesthetic duration was brief with mean duration of $29.8 \pm$ $12.3 \mathrm{~min}$. The maximum sensory level ranged from $\mathrm{T}_{3}-\mathrm{T}_{10}$. Thirty-three patients in this group required epidural supplementation (Table II) and in 29, epidural supplementation was administered before surgery due to either an incomplete block or a rapidly regressed

TABLE I Demographic and anaesthetic data (NS-not significant, NA-not available, "only one patient in this dose group received fentanyl as premedication)

\begin{tabular}{|c|c|c|c|}
\hline & $\begin{array}{l}48 \text { mg group } \\
n=35\end{array}$ & $\begin{array}{l}72 \text { mg group } \\
n=8\end{array}$ & $P$ \\
\hline age (yr) & $33 \pm 6$ & $34 \pm 6$ & NS \\
\hline $\operatorname{sex}(M / F)$ & $28 / 7$ & $4 / 4$ & NS \\
\hline height $(\mathrm{cm})$ & $173 \pm 7$ & $167 \pm 10$ & NS \\
\hline weight (kg) & $83 \pm 14$ & $74 \pm 14$ & NS \\
\hline ASA Class $1 / 2 / 3$ & $31 / 4 / 0$ & $8 / 0 / 0$ & NS \\
\hline duration of surgery (min) & $33 \pm 18$ & $23 \pm 6$ & NS \\
\hline $\begin{array}{l}\text { perioperative intravenous } \\
\text { fluid }(\mathrm{ml})\end{array}$ & $587 \pm 360$ & $600 \pm 317$ & NS \\
\hline \multicolumn{4}{|l|}{ Premedication } \\
\hline midazolam ( $\left.\mathrm{mg} \mathrm{kg}^{-1}\right)$ & $0.038 \pm 0.026$ & $0.052 \pm 0.046$ & NS \\
\hline fentanyl $\left(\mu \mathrm{g} \cdot \mathrm{kg}^{-1}\right)$ & $0.97 \pm 0.38$ & $0.88 *$ & NA \\
\hline
\end{tabular}

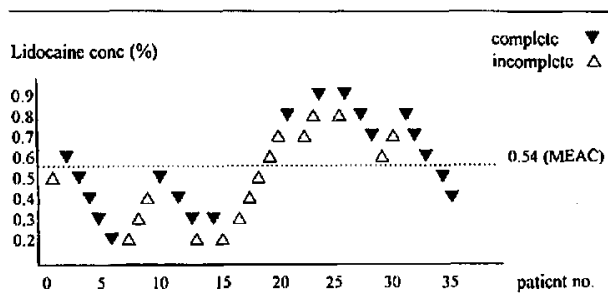

FIGURE 1 Dixon's up-and-down method in the $48 \mathrm{mg}$ group block. In contrast, all eight patients in the $72 \mathrm{mg}$ group (Figure 2) achieved complete anaesthesia with mean duration of $46.3 \pm 12.4 \mathrm{~min}$ and maximum sensory level ranged from $T_{3}-T_{8}$. Only four of eight patients required epidural supplementation (Table II) which was administered intraoperatively due to discomfort from tourniquet or at the surgical site. The concentration of $0.2 \%$ was attempted once and resulted in complete block. However, that patient developed headache and drowsiness at the time of injection. Hence, no further attempt was made to lower the concentration of the spinal solution to $<0.3 \%$ in the $72 \mathrm{mg}$ group. The value of MEAC cannot be calculated for this group but with complete anaesthesia in five consecutive patients receiving the lowest spinal concentration $(0.3 \%$ in four patients and $0.2 \%$ in one patient), this suggests that the value of $M E A C$ was $<0.3 \%$. As we decided not to lower the concentration to $0.2 \%$ further due to the side effect encountered, increase in sample size was unlikely to result in data sufficient for the estimation of the MEAC in this group. Hence, we stopped the study after eight patients were recruited in this group.

In the $48 \mathrm{mg}$ group, no correlation was found between the highest sensory level achieved and the volume or concentration of the spinal lidocaine solution used (Table III).

Only one patient in the $48 \mathrm{mg}$ group developed hypotension following administration of the spinal

TABLE II Comparison of peri-operative complications between the $48 \mathrm{mg}$ and $72 \mathrm{mg}$ group. PDPH-postdural puncture headache; TRI-transient radicular irritation.

\begin{tabular}{llll}
\hline Complication & $\begin{array}{c}48 \mathrm{mg} \\
\text { group }\end{array}$ & $\begin{array}{l}72 \mathrm{mg} \\
\text { grots }\end{array}$ & $P$ \\
\hline cpidural supplementation & $33 / 35$ & $4 / 8$ & 0.007 \\
intra-operative hypotension & $1 / 35$ & $2 / 8$ & 0.08 \\
headache related to injection & $1 / 35$ & $1 / 8$ & 0.34 \\
back pain & $11 / 35$ & $3 / 8$ & 1 \\
PDPH & $0 / 35$ & $0 / 8$ & 0.00 \\
TRI & $0 / 35$ & $1 / 8$ & 0.18 \\
urinary retention & $0 / 35$ & $1 / 8$ & 0.18 \\
\hline
\end{tabular}

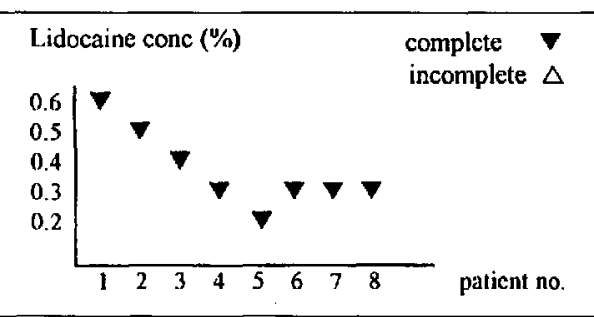

FIGURE 2 Dixon's up-and-down method in the $72 \mathrm{mg}$ group 
TABLE III Correlation between highest sensory level (expressed the number of level below 7th cervical spine) with volume and concentration of the spinal lidocaine solution administered using the multiple linear regression analysis ( $n=35$ ). The multiple linear regression coefficient $(R)$ was 0.219 and was not statistically significant $(P=0.484$; ANOVA $)$. NS-not significant.

\begin{tabular}{lll}
\hline & Pearson correlation & $P$ (one-tailed) \\
\hline sensory level $v$ s volume & -0.09 & 0.303 (NS) \\
sensory level $v$ s concentration & 0.16 & 0.180 (NS) \\
\hline
\end{tabular}

solution compared with two patients in the $72 \mathrm{mg}$ group (Table II). The patient in the $48 \mathrm{mg}$ group received lidocaine $0.2 \%$ with the highest sensory level at $T_{3}$ while both patients in the $72 \mathrm{mg}$ group received lidocaine $0.3 \%$ with the highest sensory level at $T_{2}$ and $\mathrm{T}_{3}$ respectively. One patient in the $48 \mathrm{mg}$ group developed headache at the end of injection but this resolved soon after the patient resumed the supine position. The volume and concentration of the injectate were $24 \mathrm{ml}$ and $0.2 \%$ respectively. In the $72 \mathrm{mg}$ group, one patient developed transient headache and drowsiness lasting one minute. The concentration of lidocainc used in this patient was $0.2 \%$ and the volume of injectate was $36 \mathrm{ml}$. This patient remained arousable and no intervention was required.

Postoperatively, none of the patients in either group developed postdural puncture headache. The incidence of back pain was $31.4 \%(11 / 35)$ in the $48 \mathrm{mg}$ group and $37.5 \%(3 / 8)$ in the $72 \mathrm{mg}$ group. The back pain developed was mild in all but three patients. Two patients in the $48 \mathrm{mg}$ group and one patient in the $72 \mathrm{mg}$ group described the pain as moderate and severe respectively. Only one patient developed symptoms suggestive of transient radicular irritation. This patient, in the $72 \mathrm{mg}$ group, received lidocaine $0.4 \%$ solution. No paraesthesia was elicited during the combined spinal epidural procedure for this patient. About two hours after the patient was discharged home, he developed severe "electric current" type of pain in both buttocks and thighs. He was treated with Tylenol \#3 and the pain resolved by the next morning. Finally, one patient in the $72 \mathrm{mg}$ group developed urinary retention after hospital discharge. This patient was unable to void and developed considerable bladder distention discomfort. Eventually, this resolved spontaneously around midnight on the same day. The concentration of the spinal solution used in this patient was $0.3 \%$.

\section{Discussion}

The minimum anaesthetic effective concentration (MEAC) of hyperbaric lidocaine for spinal anaesthesia has never been established although lidocaine $5 \%$ solution has been used for spinal anaesthesia for $>50 \mathrm{yr}$. The concept of MEAC is similar to the concept of minimum alveolar concentration (MAC) for an inhalational anaesthetic. In in pitro study, the MEAC for a local anaesthetic is defined as the threshold concentration of anaesthetic that is effective in blocking a nerve in a bathing solution within $10-15$ min. ${ }^{20}$ In clinical practice, we defined MEAC as the concentration at which a spinal anaesthetic produces surgical anaesthesia within $20 \mathrm{~min}$ of administration in $50 \%$ of patients. Twenty minutes was chosen as a cut-off point as complete motor and sensory block of the lower extremities was usually achieved within 20 min of the administration of intrathecal lidocaine. ${ }^{21}$ The MEAC for spinal anaesthesia is a pharmacological concept. In clinical practice, it is more useful to determine the minimum spinal anaesthetic concentration that provides effective anaesthesia in $95 \%$ of the patients (effective concentration $95 \%$ or $\mathrm{EC}_{95}$ ); as the failure rate associated with MEAC concentration is unacceptably high (50\%) for a single shot spinal procedure. As there is a paucity of information concerning the use of dilute lidocaine solutions, determination of MEAC is the logical first step before determining $\mathrm{EC}_{95}$.

In the present study, we demonstrated that the MEAC of lidocaine is much less than the $5 \%$ conventionally used. Even with very strict criteria chosen for complete anacsthesia, spinal anaesthesia can be accomplished with very dilute lidocaine solutions $(0.2-0.9 \%)$. It is important to note that the value of MEAC is dependent on the dose of spinal anaesthetic administered. The MEAC of lidocaine is $0.54 \%$ with a dose of $48 \mathrm{mg}$ but is < $0.3 \%$ with a dose of $72 \mathrm{mg}$. Following administration of spinal anaesthetic into the intrathecal space, the anaesthetic is diluted after mixing with the cerebrospinal fluid (CSF). The anaesthetic effect is dependent on the effective local anaesthetic concentration in the CSF surrounding the nerve roots. The higher the dose administered, the higher is the local anaesthetic concentration achieved. Thus, the value of MEAC of the spinal anaesthetic is inversely related to the dose administered.

In this study, a large volume of spinal anaesthetic was administered, 5.3-36 ml. Two patients experienced side effects like headache and transient drowsiness. Presumably, these neurological symptoms were related to an increase in intracranial pressure (ICP) secondary to the large volume injected into the subarachnoid space $(24 \mathrm{ml}$ and $36 \mathrm{ml})$. Addition of volume to the cerebrospinal fluid involves distention of spinal dura mater, displacement of CSF from the spinal canal to cranium and cerebral vascular compartment. The degree of change in pressure following an increase in volume depends on the initial position on the elastance curve of the cerebrospinal system. Once the volume increases to a certain threshold, the ICP increases in an exponential manner. Katzman ${ }^{22}$ noted an increase of CSF pressure 
to $600 \mathrm{~mm} \mathrm{H} \mathrm{H}_{2} \mathrm{O}$ in 5-11 min after infusion of approximate 19 to $42 \mathrm{ml}$ normal saline into the subarachnoid space. Based on Katzman's infusion study and observa. tions in the present study, it is prudent to avoid injecting > $15 \mathrm{ml}$ local anaesthetic solution into the subarachnoid space acutely.

We also found that the highest sensory level of anaesthesia achieved did not correlate with the volume of the intrathecal lidocaine solution administered despite a five-fold variation in injection volume $(5.3-24 \mathrm{ml})$ in the $48 \mathrm{mg}$ group. The distribution of hyperbaric local anaesthetic solution within the subarachnoid space is affected by gravity, patient position, dosage and volume of drug. ${ }^{23}$ Keeping the concentration of hyperbaric local anaesthetic solution constant, an increase in volume increases the total dose administered and will result in higher cephalad spread. ${ }^{24-26}$ In the present study, the absence of a volume effect on cephalad spread can be attributed to the constant dose of administration. This is supported by studies in which varying the concentration of a fixed dose of hyperbaric lidocaine $^{18,21,27}$ and bupivacaine ${ }^{28}$ resulted in no difference in cephalad spread of anaesthetic effect. Hence, the total dose is more important than the volume and concentration of anaesthetic solution in determining the spread of the anaesthetic solution in cerebrospinal fluid. ${ }^{29}$ This concept is important with the increasing use of dilute spinal lidocaine solution as there is some concern that the larger volume of dilute local anaesthetic administered likely results in a higher block.

In the present study, only one patient in the $72 \mathrm{mg}$ group developed transient neurological symptoms. Reports of transient radicular irritation (TRI) have raised considerable concern among practising anaesthetists and has been the subject of discussion in two recent editorials. ${ }^{30,31}$ Transient radicular irritation refers to the pain and/or dysesthesia in the legs or buttocks after recovery from spinal anaesthesia. The symptoms are usually mild and self-limiting, and tend to resolve within $72 \mathrm{hr}$. However, they can be severe, ${ }^{32-34}$ requiring pharmacological treatment and even readmission to hospital. ${ }^{35}$ More importantly, this may represent the lower end of the spectrum of neurotoxicity as these findings are consistent with toxicity data obtained in vitro $0^{6,7}$ and in vivo. ${ }^{8,36}$ Decreasing the lidocaine concentration has been recommended by the Food and Drug Administration in an attempt to reduce the risk of transient neurological symptoms. ${ }^{b}$ However, a recent study ${ }^{18}$ showed that the incidence of transient neurological symptoms was similar with hyperbaric lidocaine

\footnotetext{
b US Food and Drug Administration, Center for Drug Evaluation and Research, Anesthetic and Life Support Drugs Advisory Committee Meeting, June 9, 1994.
}

$2 \%$ and $5 \%$ solutions. Furthermore, these symptoms have been reported with even lower concentrations. ${ }^{21,37}$ Hence, TRI cannot be simply eliminated with dilute spinal lidocaine solution. Whether very low concentrations will reduce the risk and severity of the TRI requires more investigation in the furure.

There are limitations in our study. Firstly, the MEAC determined is a pharmacological concept. As mentioned previously, the $\mathrm{EC}_{95}$ is a more useful and practical concept for the use of single shot spinal technique. Hence, with $48 \mathrm{mg}$, we do not recommend the use of $0.54 \%$ as the concentration of spinal anaesthetic solution for clinical use as it will result in a failure rate of $50 \%$ and an unacceptably high rate of epidural supplementation. While $72 \mathrm{mg}$ spinal lidocaine solution of $0.3 \%$ results in a greater chance of success, we do not endorse this practice clinically because an extremely high volume of injectate is required. Secondly, this study was primarily designed to determine the concentration of lidocaine solution at which complete block could be achieved. Hence, there was no detailed characterisation and documentation of the profile of block regression. Furthermore, we used very strict criteria to define the completeness of block, i.e., motor and sensory block $\geq \mathrm{T}_{12}$ bilaterally. This may not be relevant or necessary clinically. For instance, some of the incomplete block noted in our patients was due to preservation of some motor function in the non-operative foot.

In summary, we established a new concept - the minimum effective anaesthetic concentration - for a spinal anaesthetic. Successful anaesthesia can be provided with very dilute lidocaine solutions $(0.2 \%$ to $0.9 \%)$ and the value of MEAC is inversely related to the dose of lidocaine administered ( $0.53 \%$ for $48 \mathrm{mg}$ compared with $<0.3 \%$ for $72 \mathrm{mg}$ ). Diluting hyperbaric lidocaine solution at fixed dose did not result in higher rostral spread. Finally, TRI can still occur with the use of very dilute spinal lidocaine solution.

\section{Appendix}

Calculation of the $95 \%$ confidence interval for the Dixon's up-and-down method

The standard deviation $\mathrm{s}=1.62 \mathrm{~d}\left(S^{2} / \mathrm{d}^{2}+0.029\right)$

and the variance $S^{2}=\frac{\Sigma f i x i^{2}-(\Sigma f i x i)^{2} / n}{n-1}$

where $d=$ concentration increment of $0.1 \%$; $\mathrm{n}=$ no. of failure blocks.

and is true as long as $\mathrm{S}^{2} / \mathrm{d}^{2}$ is greater than 0.3 . $\left(S^{2} / d^{2}=4.6\right.$ in this study)

$95 \%$ confidence interval for MEAC is $\mathrm{X} \pm 1.96 \mathrm{Gs} / \sqrt{\mathrm{n}}$ where $\mathrm{X}=$ mean (value for $\mathrm{MEAC}$ ) $G=$ constant depending on the ratio of $d / s$ ( $\mathrm{G}=0.9$ in this study) 


\section{References}

1 Fink BR. History of neural blockade. In: Cousins MJ, Bridenbaugh PO (Eds.). Neural Blockade in Clinical Anesthesia and Management of Pain, 2nd ed. Philadelphia: Lippincott, 1988: P3-24.

2 Phillips OC,Ebner H,Nelson AT, Black MH. Neurologic complications following spinal anesthesia with lidocaine: a propective review of 10,440 cases. Anesthesiology 1968; 30: 284-9.

3 Rigler ML, Drasner K, Krejcie TC, et al. Cauda equina syndrome after continuous spinal anesthesia. Anesth Analg 1991; 72: 275-81.

4 Schell RM, Brauer FS, Cole DJ, Applegate RL II. Persistent sacral nerve root deficits after continuous spinal anaesthesia. Can J Anaesth 1991; 38: 908-11.

5 Schneider $M$, Ettlin $T$, Kaufmann $M$, et al. Transient neurologic toxicity after hyperbaric subarachnoid anesthesia with 5\% lidocaine. Anesth Analg 1993; 76: $1154-7$.

6 Lambert $L A$, Lambert DH, Strichartz GR. Irreversible conduction block in isolated nerve by high concentrations of local anesthetics. Anesthesiology 1994; 80: 1082-93.

7 Bainton CR, Strichartz GR. Concentration dependence of lidocaine-induced irreversible conduction loss in frog nerve. Anesthesiology 1994; 81:657-67.

8 Kalichman MW, Powell HC, Myers RR. Quantitative histologic analysis of local anesthetic-induced injury to rat sciatic nerve. J Pharmacol Exp Ther 1989; 250: 406-13.

9 Drasner K, Rigler $M L$, Sessler DI, Stoller $M L$. Caude equina syndrome following intended epidural anesthesia. Anesthesiology 1992; 77: 582-5.

10 Toft P, Bruun-Mogensen Chr, Kristensen J, Hole P. A comparison of glucose-free $2 \%$ lidocaine and hyperbaric $5 \%$ lidocaine for spinal anaesthesia. Acta Anaesthesiol Scand 1990; 34: 109-13.

11 Kristensen J, Helbo-Hansen HS, Toft P, Hole P. Spinal anaesthesia with glucose-free $2 \%$ lignocaine. Effect of different volumes. Acta Anaesthesiol Scand 1989; 33: 53-7.

12 Manica VS, Bader AM, Fragneto R, Gilbertson L, Datta $S$. Anesthesia for in vitro fertilization: a comparison of $1.5 \%$ and $5 \%$ lidocaine for ultrasonically guided oocyte retrieval. Anesth Analg 1993; 77; 453-6.

13 Kumar A, Bala I, Bbukal I, Singh H. Spinal anaesthesia with lidocaine 2\% for Caesarean section. Can J Anaesth 1992; 39: 915-9.

14 Bodily $M N$, Carpenter RL, Owens BD. Lidocaine 0.5\% spinal anacsthesia: a hypobaric solution for short-stay perirectal surgery. Can J Anaesth 1992; 39: 770-3.

15 Chan VWS, Gartia J, Drasner K. A comparative study of hyperbaric spinal lidocaine $0.5 \%$ versus $5 \%$ for urologic surgery. Anesthesiology 1995; 83: A777.
16 Dixon WJ, Massey FJ Jr. Introduction to Statistical Analysis, 4th ed. New York: McGraw Hill, 1983; 428-49.

17 Petersen-Felix $S$, Zbinden AM, Fischer $M$, Thomson DA. Isoflurane minimum alveolar concentration decreases during anesthesia and surgery. Anesthesiology 1993; 79: 959-65.

18 Hampl KF, Schneider MC, Pargger H, Gut J, Drewe J, Drasner $K$. A similar incidence of transient neurologic symptoms after spinal anesthesia with $2 \%$ and $5 \%$ lidocaine. Anesth Analg 1996; 83: 1051-4.

19 Columb $M O$, Lyons $G$, Naughton NN, et al. Estimation of the minimum local analgesic concentration (ML.AC) of epidural chloroprocaine hydrochloride in labor. Reg Anesth 1995; 20: $\$ 96$.

20 de Jong RH. Local Anesthetics, 1st ed. St. Louis: Masby-Year Book, 1994.

21 Lit S, Pollock JE, Mulroy MF, Allen HW, Neal JM, Carpenter $R L$. Comparison of $5 \%$ with Dextrose, 1.5\% with Dextrose, and $1.5 \%$ Dextrose-free lidocaine solutions for spinal anesthesia in human volunteers. Anesth Analg 1995; 81: 697-702.

22 Katzman $R$, Hussey $F$. A simple constant-infusion manometric test for measurement of CSF absorption. I. Rationale and method. Neurology 1970; 20: 534-44.

23 Greene NM. Distribution of local anesthetic solutions within the subarachnoid space. Anesth Analg 1985; 64: 715-30.

24 Wildsmith JAW, McClure JH, Brown DT, Scott DB. Effects of posture on the spread of isobaric and hyperbaric amethocaine. $\mathrm{Br}$ J Anaesth 1981; 53: 273-8.

25 Axelsson KH, Edström HH, Sundberg AEA, Widman GB. Spinal anaesthesia with hyperbaric $0.5 \%$ bupivacaine: effects of volume. Acta Anaesthesiol Scand 1982; 26: $439-45$.

26 Sundnes $K O$, Vuagenes $P$, Skretting $P$, Lind B, Edström $H H$. Spinal analgesia with hyperbaric bupivacaine: effects of volume of solution. Br J Anaesth 1982; 54: 69-73.

27 Van Zundert AAJ, Grouls RJE, Korsten HHM, Lambert $D H$. Spinal anesthesia. Volume or concentration what matters? Reg Anesth 1996; 21 : 112-8.

28 Bengtsson $M$, Edström $H H$, Löfström JB. Spinal analgesia with bupivacaine, mepivacaine and tetracaine. Acta Anaesthesiol Scand 1983; 27: 278-83.

29 Sheskey MC, Rocco AG, Bizzarri-Schmid M, Francis $D M$, Edstrom $H$, Covino BG. A dose-response study of bupivacaine for spinal anesthesia. Anesth Analg 1983; 62: 931-5.

30 de Jong $R H$. Last round for a "heavyweight?" Anesth Analg 1994; 78: 3-4. 
31 Carpenter $R L$. Hyperbaric lidocaine spinal anesthesia: do we need an alternative? Anesth Analg 1995; 81 : 1125-8.

32 Sjösröm $S$, Bläss J. Severe pain in both legs after spinal anaesthesia with hyperbaric $5 \%$ lignocaine solution. Anaesthesia 1994; 49: 700-2.

33 Pinczower GR, Chadwick $H S$, Woodland $R$, Lowmiller $M$. Bilateral leg pain following lidocaine spinal anaesthesia. Can J Anacsth $1995 ; 42 ; 217-20$.

34 Rodriguez-Chinchilla $R$, Radgriguez-Pont A, Pintanel $T$, Vidal-López F. Bilateral severe pain at L3-4 after spinal anaesthesia with hyperbaric $5 \%$ lignocaine. Br J Anaesth 1996; 76: 328-9.

35 Fenerty J, Sonner J, Sakura S, Drasner $K$. Transient radicular pain following spinal anesthesia: review of the literature and report of a case involving $2 \%$ lidocaine. Int J Obstet Anesth 1996; 5: 32-5.

36 Drasner K, Sakura S, Chan VWS, Bollen AW, Ciriales $R$. Persistent sacral sensory deficit induced by intrathecal local anesthetic infusion in the rat. Anesthesiology 1994; 80: 847-52.

37 Pollock JE, Liu SS, Neal JM, Stephenson CA. The importance of lidocaine concentration in the development of transient radiocular irritation. Reg Anesth 1997; 22: \$85. 